\title{
Termal kağıtlardaki bisfenol A'nın saptanması için optimizasyon çalışması
}

\author{
Şana SUNGUR*, Fidan KANAN \\ Mustafa Kemal Üniversitesi Fen-Edebiyat Fakültesi, Kimya Bölümü, Hatay \\ Geliş Tarihi (Recived Date): 17.08.2018 \\ Kabul Tarihi (Accepted Date): 20.09.2018
}

\section{Özet}

Bu çalışmada, termal kağıtlardaki bisfenol A'nın (BPA) kantitatif olarak saptanması için kesin ve hassas bir yöntem geliştirilmiştir. BPA termal kă̆ıtlardan asetonitril-su karışımı ile ekstrakte edilmiştir. BPA'nın ektraksiyon verimi üzerine organik çözücü konsantrasyonunun, ekstraksiyon sicakliğg ve süresinin, pH'ın etkileri incelenmiştir. Optimize edilen koşullar altında (asetonitril:su oranı 40:60, pH=7, $60^{\circ} \mathrm{C}^{\prime}$ de, 8 saat), geliştirilen metot beş farklı tipteki termal kağıttan (kasa fişi, POS cihazı fişi, hastane barkodu, ATM fişi, uçak bileti) BPA'nın ekstrakte edilmesi amacıyla uygulanmış ve BPA konsantrasyonları 8.91-10.27 mg $\mathrm{g}^{-1}$ aralığında saptanmıştır. Ayrıca, 5 ve $10 \mathrm{mg}$ $g^{-1}$ BPA seviyelerindeki spike örnekler için \% RSD değerleri sirasiyla 1.80 ve 2.90 olarak belirlenmiştir.

Anahtar kelimeler: Termal kağıt, bisfenol A (BPA), ekstraksiyon.

\section{Optimization study for the determination of bisphenol A in thermal printing papers}

\begin{abstract}
In this study, a sensitive and accurate method for the quantitative determination of bisphenol A (BPA) in thermal printing paper was developed and validated. BPA was extracted from the thermal printing papers using acetonitrile-water. The effects of organic solvent concentration, extraction temperature and time, $\mathrm{pH}$ were investigated. Under the optimized conditions (acetonitrile:water 40:60, v/v, $p H=7,60^{\circ} \mathrm{C}, 8$ hours), the proposed method was applied to the determination of BPA in five types of thermal printing papers (receipt, POS receipt, hospital barcode, ATM receipt, flight ticket), and
\end{abstract}

\footnotetext{
*SSana SUNGUR, sungur@mku.edu.tr, http://orcid.org/0000-0001-7370-8972

Fidan KANAN, fdnclk.fc@gmail.com, http://orcid.org/0000-0001-5272-5351
} 
the concentration of BPA was found in the range of 8.91-10.27 $\mathrm{mg}^{-1}$. Furthermore, spiked RSD \% of BPA at 5 and $10 \mathrm{mg} \mathrm{g}^{-1}$ was found to be 1.80 and 2.90 , respectively.

Keywords: Thermal printing paper, bisphenol A (BPA), extraction.

\section{Giriş}

Bisfenol A (2,2-bis(4-hidroksifenil)propan), iki fenol ve polikarbonat moleküllerinin birleşmesiyle elde edilen östrojenik endokrin bozucu bir monomerdir. Günümüzde özellikle plastikleri sertleştirmek amacıyla kullanılan BPA, dünyada yıllık olarak 2-3 milyon tonu aşkın bir üretime sahiptir [1]. Bisfenol A'ya maruziyet en çok oral yolla gerçekleşmektedir. Bunun yanı sıra, solunum ve deri yoluyla da maruziyet söz konusudur. Amerika Çevre Koruma Ajansı (EPA), 1988 yılında, BPA için tolere edilebilir günlük alım miktarını $0.05 \mathrm{mg} / \mathrm{kg}$ vücut ağırlığı/gün olarak belirlemiştir. 2002 yılında Avrupa Birliği bu değeri $0.01 \mathrm{mg} / \mathrm{kg}$ vücut ağırlığı/gün olarak kabul etmiştir [2]. Türkiye'deki BPA'nın yasal sınır değerleri Avrupa ile uyumludur.

Başlangıçta BPA çevresel zayıf bir östrojen olarak kabul edilmiştir. Fakat daha sonraki çalışmalarda BPA'nın çok düşük konsantrasyonlarda bile, nukleus dışındaki reseptörlere bağlanarak doku ve hücrelerin fizyolojik fonksiyonlarını çok yönlü etkileyen özellikleri olduğu gösterilmiştir. Bisfenol A, genler ve proteinler ile etkileşime girebilmektedir. Yapılan bir çalışmada 1232 tane gen ve protein üzerindeki BPA etkisinin analizleri sonucunda, kalp, böbrek ve karaciğer üzerinde toksik bir etki oluşturabileceği anlaşılmıştır [3]. Bisfenol A'nın ksenöstrojene çok benzer bir özellikte olması onun bir endokrin bozucu olarak işlev görmesine sebep olmaktadır. Yapılan çalışmalarda BPA'nın insan ve hayvanların endokrin sistemine etkisinden dolayı, üreme sisteminin yanı sıra vücut gelişimini ve davranışlarını etkilendiği de ifade edilmiştir [4].

Termal baskı, kasa fişleri, ATM kağıtları, uçak biletleri, bagaj etiketleri, fakslar gibi çok çeşitli ticari uygulamalarda kullanılmaktadır. Termal baskı işleminde, basılı görüntü 1sıya duyarlı termal kağıdın üzerinden bir baskı kafasının geçmesi ile oluşturulmaktadır. Isının etkisiyle termal kağıtta renk değişimi meydana gelmektedir. $\mathrm{Bu}$ olay termokromizm olarak isimlendirilmektedir. Bu işlemlerde kullanılan termokromik kağıt iki tabakadan oluşmaktadır. Altta normal standart bir kağıt, üstünde ise 1sıya duyarlı bir tabaka bulunmaktadır. Isıya duyarlı tabaka termokromik boya, zayıf asidik renk değiştirici (BPA) ve çözücü olmak üzere 3 bileşenden ibarettir. Çözücü olarak genellikle erime noktası $45-65^{\circ} \mathrm{C}$ arasında olan uzun zincirli alifatik bileşikler (doymuş asitler, amidler, alkoller) kullanılmaktadır. Aktif bileşenler çözücü içerisinde çözünmekte ve ısıya duyarlı tabakanın üzerinden sıcak baskı kafasının geçmesi ile renk ortaya çıkmaktadır. Termokromik boyaların çoğu spirolaktonlardır ve en yaygın olarak kullanılanı da kristal viyole laktondur. Bu boya çevre sıcaklığında renksiz olup, baskı kafası aracılığıyla çözücünün erime noktasının üzerindeki bir sıcaklığa ulaşıldığında BPA boya ile etkileşerek mavi rengin oluşmasına neden olmaktadır [5].

Sadece Avrupa'da 1 yıl içerisinde termal kağıt üretiminde 1800 ton BPA kullanılmıştır. Liao ve Kannan, Japonya, Kore ve Viyetnam'dan 103 adet termal kağıt örneği alarak BPA içeriklerini saptamışlardır. İnceledikleri termal kağıtların \% 94'ünde ortalama olarak $13.9 \mathrm{mg} \mathrm{g}^{-1}$ BPA bulunduğunu tespit etmişlerdir [6]. Zalko ve arkadaşları, bir günde cilt tarafından absorplanabilecek BPA miktarını insanlar üzerinde herhangi bir 
deneme yapmaksızın hesap yoluyla 17.5 - $1300 \mathrm{ng}$ /gün olarak belirlemişlerdir. Bu hesaplamaları yaparken, ameliyatlar neticesinde ortaya çıkan insan derileri üzerinde yaptıkları çalışmalar sonucunda belirledikleri, 1 günde insan derisinin absorblayabileceği maksimum BPA miktarından yararlanmışlardır [7]. Termal kağıtların BPA içeriği ile ilgili olarak gerçekleştirilen bir diğer çalışmada ise, çeşitli mağazalardan 13 adet termal kağıt alınmış ve BPA içerikleri $8-17 \mathrm{~g} / \mathrm{kg}$ olarak belirlenmiştir. Sonrasında, bu kağıtlara $1 \mathrm{~s}, 5 \mathrm{~s}$ ve $60 \mathrm{~s}$ dokunma neticesinde parmaklara sırasıyla yaklaşık olarak $0.4 \mu \mathrm{g}, 1.18 \mu \mathrm{g}$ ve $1.5 \mu \mathrm{g}$ BPA geçtiğini saptamışlardır. Ayrıca, cildin sslak, nemli ya da yağlı olmasına bağlı olarak BPA geçişinin nasıl değiştiğini de incelemişlerdir. Cilt ıslak ya da yağlı olduğunda BPA geçişinin yaklaşık 10 kat daha fazla olduğunu ifade etmişlerdir [8]. Termal kağıtlardan kaynaklanan BPA maruziyeti ile ilgili olarak gerçekleştirilen diğer bir çalışmada da, Kolombiya' daki 50 mağazadan termal kağıt örnekleri alınmış ve BPA içerikleri 11.5-26.3 mg/g olarak belirlenmiştir [9].

Literatürde, gıdalardaki ya da çevresel örneklerdeki BPA'nın belirlenmesine yönelik olarak kullanılan çok sayıda analitik yöntem bulunmaktadır. Bununla birlikte, bu çalışmaların çoğu sıvı örnekler üzerine yoğunlaşmıştır. Kağıt ve kağıt ürünleri gibi katı örneklerdeki BPA'nın saptanmasına ilişkin çalışmalar ise, oldukça sınırlı sayıdadır. Katı örneklerdeki BPA'nın belirlenebilmesi için gerçekleştirilen çalışmalarda büyük miktarlarda metanol ya da etanol gibi ekstraksiyon çözücüleri kullanılmaktadır. Bu çalışmada geliştirilen metodun en büyük avantajı, kullanılan çözücü miktarının oldukça az olması ve dolayısıyla da yöntemin maliyetinin düşük olmasıdır.

\section{Deneysel çalışmalar}

\subsection{Malzeme}

BPA standardı ( $\geq 99$ saflıkta) Sigma-Aldrich (U.K)'den satın alındı. Diğer tüm kimyasallar Merck (Darmstadt, Almanya)'den temin edildi. Bütün kimyasallar en azından \% 99.5 saflıkta kullanıldı. Her bir gruptan (kasa fişi, POS cihazı fişi, hastane barkodu, ATM fişi, uçak bileti) 10'ar adet olmak üzere toplam 50 adet termal kağıt örneği Hatay bölgesinden temin edildi.

\subsection{Termal kă̆gtlardan BPA ekstraksiyonu}

Her bir termal kağıttan yaklaşık $100 \mathrm{mg}$ tartılarak, $10 \mathrm{ml}$ pH'ı fosfat tamponu ve $1 \mathrm{M}$ $\mathrm{NaOH}$ kullanılarak 7'ye ayarlanmış olan asetonitril:su (hacimce 40:60) karışımına daldırılmış ve $60{ }^{\circ} \mathrm{C}$ 'de 8 saat süreyle karıştırılmıştır. Daha sonra süzme işlemi uygulanmış ve elde edilen süzüntüler BPA analizi için HPLC'ye verilmiştir.

\subsection{BPA analizi}

Örneklerdeki BPA miktarları HPLC (Shimadzu LC20A model) aracıllı̆ıyla tayin edilmiştir. Kolon olarak, Inertsil ODS-3 $5 \mu \mathrm{m}(4.6$ x $250 \mathrm{~mm})$ kolon ve dedektör olarak da fotodiyot dizisi dedektörü (SPD - M20A) kullanılmıştır. Hareketli faz olarak asetonitril:su (hacimce 40:60) karışımı kullanılmış, akış hızı $1 \mathrm{ml} /$ dak ve kolon sıcaklığı $40{ }^{\circ} \mathrm{C}$ olacak şekilde ayarlanmıştır.

\subsection{Kalite kontrol}

Bütün analizler her bir örnek için üçer kez tekrarlanmıştır. Uygulanan HPLC koşulları altında BPA piki 17.4 dakikada gelmiştir. BPA'nın $0.5-20 \mathrm{mg} \mathrm{g}^{-1}$ konsantrasyonları 
arasında standart çözeltileri hazırlanmıș ve bu çözeltilerden yararlanılarak kalibrasyon doğrusu oluşturulmuştur $\left(\mathrm{R}^{2}=0.9993\right)$. BPA için 20 'şer adet şahit numunesine ait ölçümlerin standart sapmaları hesaplanarak LOD $\left(0.010 \mathrm{mg} \mathrm{g}^{-1}\right)$ ve LOQ $\left(0.033 \mathrm{mg} \mathrm{g}^{-1}\right)$ değerleri belirlenmiştir. Ayrıca, 5 ve $10 \mathrm{mg} \mathrm{g}^{-1} \mathrm{BPA}$ içeren spike referans örneklere art arda beş ekstraksiyon uygulanmıştır. 5 ve $10 \mathrm{mg} \mathrm{g}^{-1}$ BPA seviyelerindeki spike örnekler için \% RSD değerleri sırasıyla 1.80 ve 2.90 olarak belirlenmiştir. Benzer şekilde geri kazanım yüzdeleri de 92.6 ve 103.4 olarak tespit edilmiştir.

\section{Sonuçlar ve tartışma}

BPA'nın ektraksiyon verimi üzerine organik çözücü konsantrasyonunun, ekstraksiyon sicaklığı ve süresinin, pH'ın etkilerini incelemek amacıyla, tüm termal kağıt örnekleri küçük parçalara ayrılarak karıştırılmış ve deneysel çalışmalar bu karışımdan alınan tartımlarla gerçekleştirilmiştir.

BPA ekstraksiyonu üzerine organik çözücü konsantrasyonunun etkisi, asetonitril:su oranları hacimce 40:60; 50:50 ve 60:40 olacak şekilde ayarlanarak denenmiştir. Karışımların pH'ı fosfat tamponu ve $1 \mathrm{M} \mathrm{NaOH}$ 'den yararlanılarak 7'ye getirilmiş ve karıştırma işlemi $60^{\circ} \mathrm{C}^{\prime}$ de 8 saat süreyle uygulanmıştır. Elde edilen eğri Şekil 1'de gösterilmiştir. Şekilden de görüleceği gibi, termal kağıtlardan en fazla BPA ekstraksiyonunun asetonitril:su oranı hacimce 40:60 olduğunda gerçekleştiği saptanmıştır.

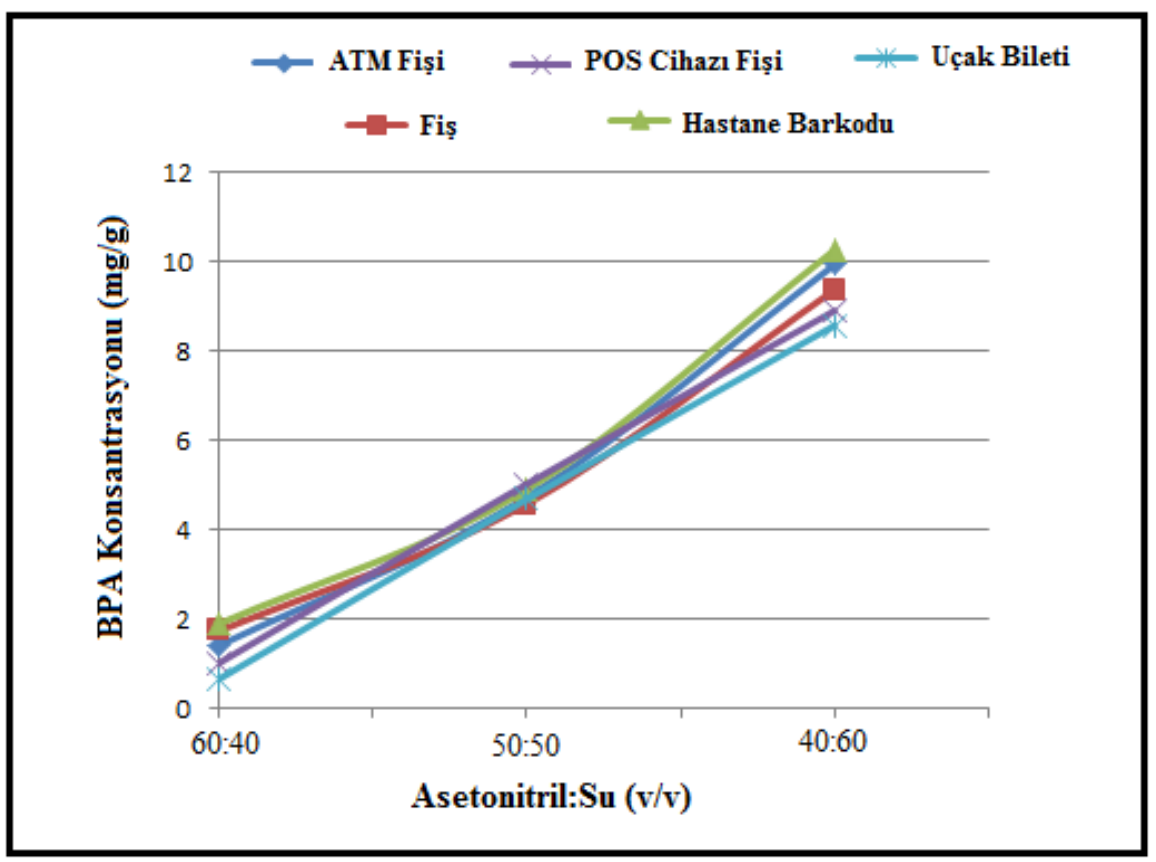

Şekil 1. BPA ekstraksiyonu üzerine organik çözücü konsantrasyonunun etkisi.

BPA ekstraksiyonu üzerine, ekstraksiyon sicaklığ ve süresinin etkisini incelemek amacıyla gerçekleştirilen deneylerde, sıcaklık $25^{\circ} \mathrm{C}, 40{ }^{\circ} \mathrm{C}, 60^{\circ} \mathrm{C}$ ve $80^{\circ} \mathrm{C}$ olarak, süreler ise 3, 5, 8 ve 10 saat olarak ayarlanmıştır. Deneyler, asetonitril:su oranı hacimce 
40:60 ve $\mathrm{pH}=7$ olan çözeltilerde gerçekleştirilmiştir. Elde edilen eğriler Şekil 2 ve 3 'de verilmiştir. Termal kağıtlardan en fazla BPA ekstraksiyonunun $60^{\circ} \mathrm{C}$ sicaklıkta ve 8 saatlik karıştırma sonucunda gerçekleştiği görülmüştür.

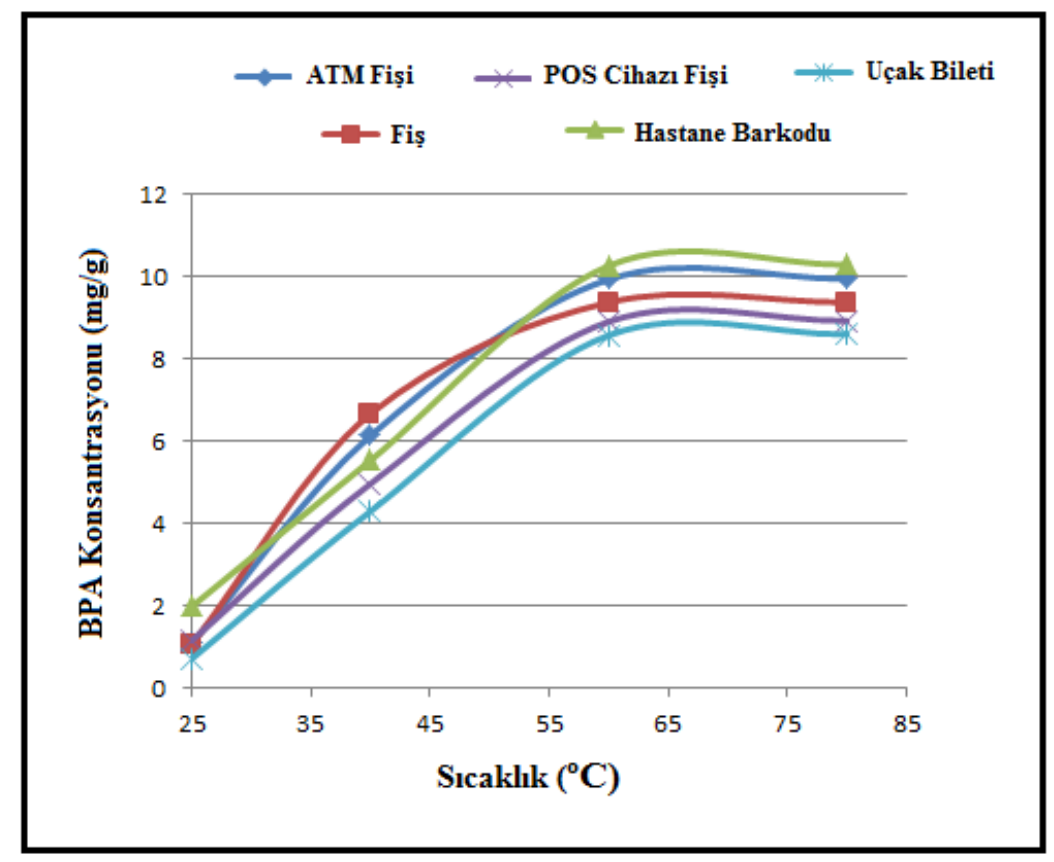

Şekil 2. BPA ekstraksiyonu üzerine sıcaklığın etkisi.

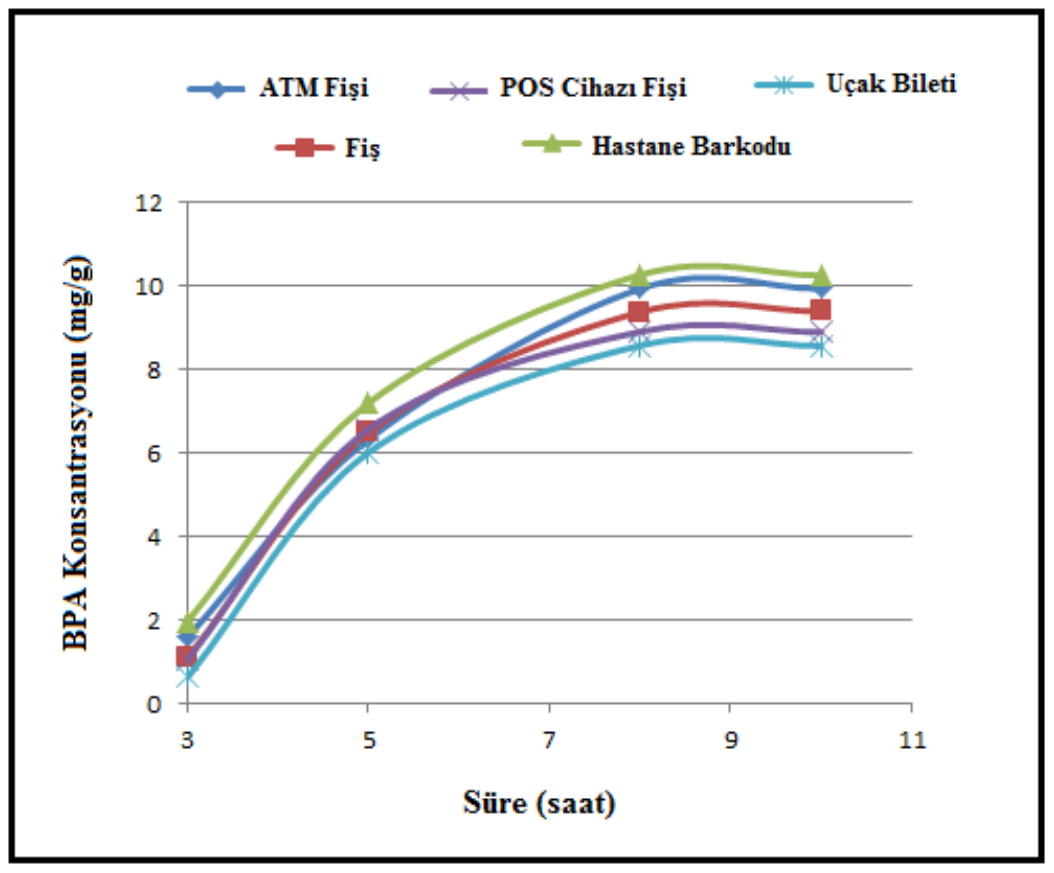

Şekil 3. BPA ekstraksiyonu üzerine sürenin etkisi. 
BPA ekstraksiyonu üzerine $\mathrm{pH}$ 'ın etkisi, $\mathrm{pH}$ değerleri 3, 5, 7 ve 9 olacak şekilde ayarlanarak denenmiştir. Benzer şekilde, deneyler, asetonitril:su oranı hacimce 40:60 ve $\mathrm{pH}=7$ olan çözeltilerde $60{ }^{\circ} \mathrm{C}$ 'de gerçekleştirilmiştir. Elde edilen eğriler Şekil 4' de verilmiştir. Termal kağıtlardan en fazla BPA ekstraksiyonu pH 7'de gerçekleşmiştir.

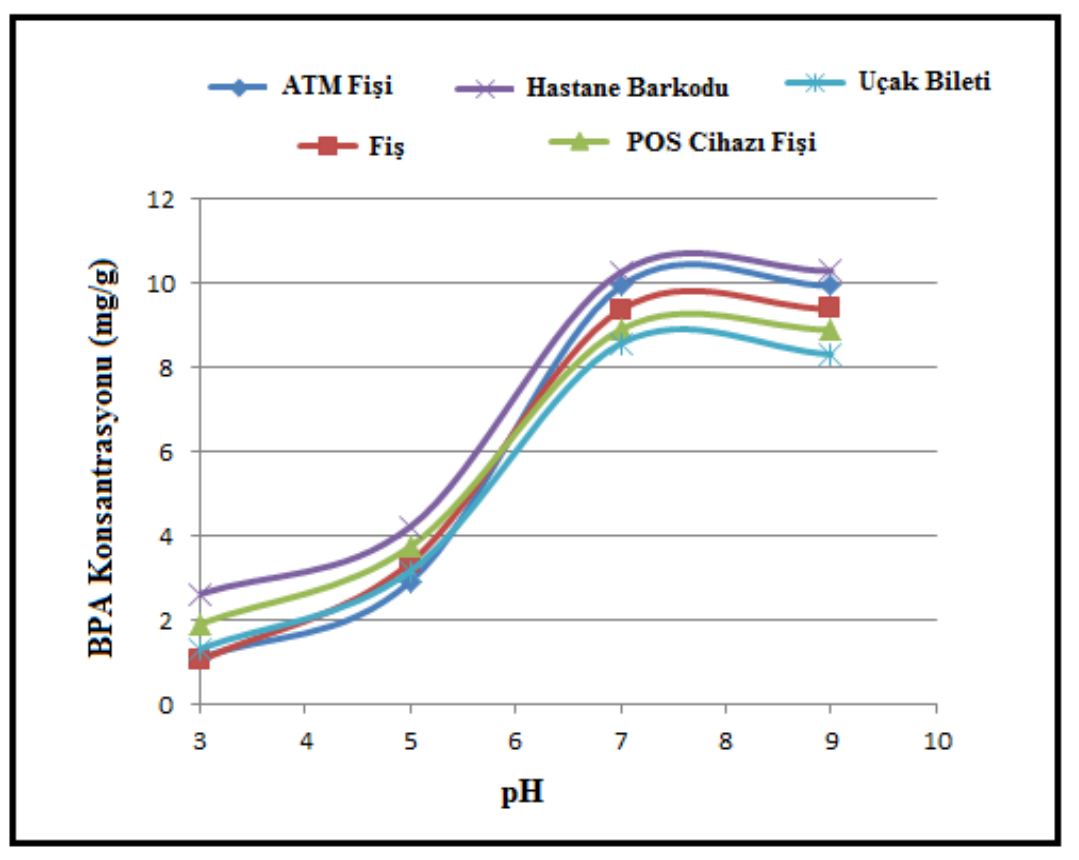

Şekil 4. BPA ekstraksiyonu üzerine pH'in etkisi.

Belirlenen optimum şartlar kullanılarak, toplanan termal kağıtların BPA içerikleri belirlenmiş ve elde edilen sonuçlar Tablo 1'de verilmiştir. Termal kağıtların ortalama BPA içerikleri 8.91 - $10.27 \mathrm{mg} \mathrm{g}^{-1}$ arasında tespit edilmiştir. Ortalama BPA konsantrasyonları hastane barkotlarında $10.27 \mathrm{mg} \mathrm{g}^{-1}$, kasa fişlerinde $9.38 \mathrm{mg} \mathrm{g}^{-1}$, POS cihazı fişlerinde $8.91 \mathrm{mg} \mathrm{g}^{-1}$, ATM fişlerinde $9.94 \mathrm{mg} \mathrm{g}^{-1}$ ve uçak biletlerinde $8.58 \mathrm{mg}$ $\mathrm{g}^{-1}$ olarak bulunmuştur.

Tablo 1. Termal kağıtların BPA içerikleri

\begin{tabular}{|c|c|c|}
\hline Örnek & Derece & $\begin{array}{c}\text { BPA Konsantrasyonu } \\
(\mathbf{m g} / \mathbf{g})\end{array}$ \\
\hline \multirow{3}{*}{ Hastane barkodu } & Minimum & $9.95 \pm 0.18$ \\
\cline { 2 - 3 } & Maksimum & $10.53 \pm 0.20$ \\
\cline { 2 - 3 } & Ortalama & $10.27 \pm 0.20$ \\
\hline \multirow{3}{*}{ Kasa fişi } & Minimum & $9.14 \pm 0.26$ \\
\cline { 2 - 3 } & Maksimum & $10.05 \pm 0.29$ \\
\cline { 2 - 3 } & Ortalama & $9.38 \pm 0.27$ \\
\hline \multirow{3}{*}{ POS cihazı fişi } & Minimum & $8.43 \pm 0.24$ \\
\cline { 2 - 3 } & Maksimum & $9.38 \pm 0.27$ \\
\cline { 2 - 3 } & Ortalama & $8.91 \pm 0.26$ \\
\hline \multirow{3}{*}{ ATM fişi } & Minimum & $9.59 \pm 0.15$ \\
\cline { 2 - 3 } & Maksimum & $10.22 \pm 0.18$ \\
\cline { 2 - 3 } & Ortalama & $9.94 \pm 0.16$ \\
\hline \multirow{2}{*}{ Uçak bileti } & Minimum & $8.14 \pm 0.29$ \\
\cline { 2 - 3 } & Maksimum & $9.01 \pm 0.33$ \\
\cline { 2 - 3 } & Ortalama & $8.58 \pm 0.31$ \\
\hline
\end{tabular}


Sonuç olarak, geliştirilen metot termal kağıt örneklerinden BPA'nın kantitatif olarak belirlenmesi için başarıyla uygulanmıştır. Ucuz, kolay ve hızlı bir yöntem olarak kağıt ve kağıt ürünlerindeki BPA tayinlerinde rahatlıkla kullanılabilecek bir yöntemdir.

\section{Kaynaklar}

[1] Er, B. ve Sarımehmetoğlu, B., Gıdalarda bisfenol A varlığının değerlendirilmesi, Veteriner Hekim Derneği Dergisi, 82, 1, 69-74, (2011).

[2] Kang, J.H., Kondo, F. ve Katayama, Y., Human exposure to bisphenol A, Toxicology, 226, 79-89, (2006).

[3] Singh, S. ve Li, S.S.L., Epigenetic effects of environmental chemicals bisphenol A and phthalates, International Journal of Molecular Sciences, 13, 1014310153, (2012).

[4] Wolstenholme, J.T., Rissman, E.F. ve Connelly, J.J., The role of bisphenol A in shaping the brain, epigenome and behavior, Hormones and Behavior, 59, 296305, (2011).

[5] Mendum, T., Stoler, E., VanBenschoten, H. ve Warner, J.C., Concentration of bisphenol A in thermal paper, Green Chemistry Letters and Reviews, 4, 1, 8186, (2011).

[6] Liao, C. ve Kannan, K., Widespread occurrence of bisphenol A in paper and paper products: Implications for human exposure, Environmental Science and Technology, 45, 9372-9379, (2011).

[7] Zalko, D., Jacques, C., Duplan, H., Bruel, S. ve Perdu, E., Viable skin efficiently absorbs and metabolizes bisphenol A, Chemosphere, 82, 424-430, (2011).

[8] Biedermann, S., Tschudin, P. ve Grob, K., Transfer of bisphenol A from thermal printer paper to the skin, Analytical and Bioanalytical Chemistry, 398, 571576, (2010).

[9] Hormann, A.M., Saal, F.S., Nagel, S.C., Stahlhut, R.W., Moyer, C.L. ve Ellersieck, M.R., Holding thermal receipt paper and eating food after using hand sanitizer results in high serum bioactive and urine total levels of bisphenol A (BPA), Plos One, 9, 10, 1-12, (2014). 